\title{
Visões litorâneas - o Litoral Norte do Rio Grande do Sul sob o olhar de Saint-Hilaire, Seidler e Roquette-Pinto
}

\author{
Coastal views - the North Coast of Rio Grande do Sul \\ under the watchful of Saint-Hilaire, Seidler and \\ Roquette-Pinto
}

Marcos Witt*

Resumo: O presente texto tem como objetivo comparar o que foi visto e escrito por Saint-Hilaire, Seidler e Roquette-Pinto em relação ao Litoral Norte do Rio Grande do Sul (LNRS). Os dois primeiros viajantes passaram por esta região nas primeiras décadas do século XIX; já o terceiro, excursionou pelo litoral no ano de 1906. Portanto, há uma diferença de, mais ou menos, cem anos entre estas visões litorâneas. A natureza e seus atributos são o enfoque principal deste exercício de comparação.

Palavras-chave: Visões. Litoral Norte. Viajantes.

Abstract: The aim of this text is to compare what was seen and written by SaintHilaire, Seidler and Roquette-Pinto in relation to The North Coast of Rio Grande do Sul (NCRGS). The two first travelers passed through this region in the first decade of XIX century; the third one however toured by the coast in 1906. Therefore there is a difference of approximately one hundred years in between these coastal views. The nature and its attributes are the principal focus of this comparison exercise.

Keywords: Views. North Coast. Travelers.

* Professor no Programa de Pós-Graduação em História da Universidade do Vale do Rio dos Sinos - UNISINOS; Doutor em História pela Pontifícia Universidade Católica do Rio Grande do Sul - PUCRS; associado ao Instituto Histórico de São Leopoldo. E-mail: <marcoswitt@terra.com.br>. 
"e por isso fui anotando, o mais que pude, todos os aspectos daquela belíssima porção do território brasileiro cujo valor econômico não é ainda conhecido como merece."

(RoQUETTE-PINTO, 1962, p. 11)

O Litoral Norte do Rio Grande do Sul (LNRS) tem como limites, de um lado, as cidades de Santo Antônio da Patrulha, um dos quatro primeiros municípios do Rio Grande do Sul, criado em 1809, e de Osório, hoje mais conhecida em função da energia eólica, e de outro, a praia de Torres, junto ao rio Mampituba. No total, são 24 municípios que formam a região denominada de LNRS. ${ }^{1}$ Há muito tempo que a geografia e a natureza litorânea têm despertado o interesse de inúmeros viajantes, pintores, escritores, pesquisadores, agentes do turismo, entre outros que se encantam com as dádivas existentes entre o mar e a Serra Geral. De fato, numa área não muita extensa, temos o mar (ou a praia), a planície costeira com as lagoas, os rios e riachos que perpassam toda a região, a Serra Geral e os Campos de Cima da Serra. Todos esses atributos foram percebidos por aqueles que, em algum momento e por algum motivo, passaram pelo LNRS.

Conforme diz o título deste texto, o foco da análise foi direcionado à produção escrita de Saint-Hilaire (2002, p. 11-26), Seidler (1980, p. 219-238) e Roquette-Pinto (1962), os quais excursionaram pelo LNRS em períodos distintos: os dois primeiros no início do século XIX e, o terceiro, na primeira década do século XX. Portanto, há, mais ou menos, 90 anos entre uma passagem e outra. Como os três viajantes abordaram a questão da geografia e da natureza em seus escritos, é possível investigar, através dos seus testemunhos, se houve mudanças no cenário litorâneo no decurso de quase um século. A passagem de Saint-Hilaire e de Seidler pelo LNRS está inserida num contexto de visita e descoberta das riquezas brasileiras impulsionadas pela vinda da Corte portuguesa, em 1808. O francês Saint-Hilaire, como cientista, integrou o grupo que percorreu diversas regiões do Brasil, a fim de mapear fauna, flora e agrupamentos humanos, indígenas ou já nacionais.

24 municípios compõem a AMLINORTE (Associação dos Municípios do Litoral Norte do Rio Grande do Sul): Arroio do Sal, Balneario Pinhal, Capão da Canoa, Capivari do Sul, Caraá, Cidreira, Dom Pedro de Alcântara, Imbé, Itati, Mampituba, Maquiné, Morrinhos do Sul, Mostardas, Osório, Palmares do Sul, Rolante, Santo Antônio da Patrulha, Tavares, Terra de Areia, Torres, Tramandaí, Três Cachoeiras, Três Forquilhas, Xangri-la. 
Seidler, que não era um cientista, usou o litoral brasileiro como área de deslocamento. Porém, mesmo que sua passagem pelo Sul tenha tido outros objetivos, soube registrar o que observou. O hábito das anotações, na forma de diários, cadernos de campo e outros tipos de relatório, fazia parte do cotidiano de praticamente todos os viajantes.

Metodologicamente, optou-se por trabalhar os três viajantes individualmente para, depois, se estabelecer algumas comparações entre eles. A sequência das análises se deu em razão da cronologia das excursões, isto é, Saint-Hilaire foi o primeiro a passar pelo LNRS; Seidler, o segundo; e Roquette-Pinto, o terceiro. Da mesma forma, os três testemunhos escritos foram interpretados como relatos de viajantes, os quais, muitas vezes, revelam o olhar de alguém que vem de fora, do estrangeiro que se encanta com as belezas do Brasil, mas, também, que supervaloriza ou se espanta com o exótico. Afora isso, os escritos foram analisados como representação e não como a descrição do real; teve-se ciência, o tempo todo, de que o que ficou registrado foi a visão de alguém que passou pelo LNRS. Ao se trabalhar a partir desta prerrogativa, fezse necessário analisar o discurso presente em cada registro. Conforme Eliane Fleck:

A literatura de viagem constitui-se numa das principais fontes para a historiografia, sendo também amplamente utilizada em trabalhos de literatura, sociologia e antropologia. Deve-se, sempre, considerar que as descrições e informações constantes nesses relatos constituem, na verdade, representações, reinvenções da realidade, produzidas com base nas visões de mundo dos viajantes que incidem sobre a feitura e sobre a transformação historiográfica de uma memória. (Fleck, 2006, p. 273).

Em relação a Saint-Hilaire ${ }^{2}$, ele chegou a Torres em 5 de junho de 1820. Da praia, destacou os "montes" os quais "avançam mar adentro".

\footnotetext{
"Cumpre citar também o botânico francês Augusto de Saint-Hilaire, que durante os anos de 1816 a 1822 percorreu grande extensão das terras brasileiras, descrevendo minuciosamente e com grande penetração as províncias do Rio de Janeiro, Espírito Santo, Minas Gerais, Goiás, São Paulo (inclusive o Paraná), Santa Catarina, Rio Grande do Sul e a Cisplatina. Além das suas conhecidas obras de viagem, Voyages dans l'intérieur du Brésil (em vários volumes), que só muito mais tarde vieram a lume, publicou trabalhos científicos sobre a flora brasileira e deu algumas contribuições de valor ao estudo das línguas indígenas, apresentando, entre outras, pequenos vocabulários malali, monoxó, macuni, maxacali e coroado". Ver: Oberacker, (1997, p. 120-121). De acordo com Eliane Fleck, "o botânico francês Auguste de Saint-Hilaire veio ao Brasil em 1816, acompanhando a missão extraordinária do duque de Luxemburgo, cujo objetivo era resolver o conflito que opunha Portugal e França quanto à posse legítima da Guiana". Ver: Fleck, (2006, p. 273-307, p. 297). [Coleção História Geral do Rio Grande do Sul].
} 
A construção da igreja e a finalização do forte, bem como o trabalho efetuado por índios ("uns vieram das Missões, outros de Entre-Rios e do Paraguai"), foram alvo de suas considerações. Sobre as primeiras páginas do seu relato, elas são, de fato, dirigidas à descrição das torres e da pequena vegetação que a acompanha. As torres são o que há de maior no cenário litorâneo; em contraste, estão a aparência dos índios com "fisionomia verdadeiramente ignóbil", segundo Saint-Hilaire e a pobreza das choupanas. No que tange à pobreza das choupanas, da vegetação e dos campos, é possível que esse cenário por vezes melancólico tenha colaborado para entristecer, ainda mais, o espírito do cientista. Ou, então, seu espírito entristecido, facilmente identificado quando o autor faz comparações com a França e se recorda de sua mãe, colaborou para que Saint-Hilaire visse e registrasse o cenário investigado de forma acinzentada e menos colorida.

Embora cientista, Saint-Hilaire lançou um olhar sobre os indígenas que encontrou no LNRS que, hoje, pode ser analisado sob o crivo de (pré)conceitos. Fleck, ao analisar os registros do "brigadeiro don Felix de Azara, que esteve na região do Prata entre 1781 e 1801" (Fleck, 2006, p. 292), constatou que Azara "não se desvinculou dos seus (pré) conceitos, associando-os [os indígenas] a selvagens e animais". (Fleck, 2006, p. 295). Por certo, o estranhamento e o olhar eurocêntrico de alguns viajantes dificultaram e/ou impediram que a relação cientistaobjeto se desse de forma mais objetiva e criteriosa. De igual modo, Saint-Hilaire parece ter se chocado não somente com as choupanas, mas, de acordo com Fleck, com o fato de "os nativos da terra, mesmo ricos, não [possuírem] lareiras em suas casas, diferentemente do mais humilde camponês da França" (Fleck, 2006, p. 297). Novamente, a comparação levou em conta cenários distintos, isto é, Brasil e França; pelas palavras do cientista, haveria melhores condições de vida no território francês do que no brasileiro. Como estudioso, aspectos sociais e econômicos poderiam ter pautado as observações de Saint-Hilaire, o que o levaria, com certeza, a outros resultados e interpretações.

Ao cruzar o LNRS de Torres a Viamão, Saint-Hilaire registrou as culturas que eram plantadas pelos pequenos agricultores. A mandioca já se constituía o principal produto da região, acompanhada de milho, feijão, cana-de-açúcar e trigo. Ao passar pelas lagoas, constatou que as plantações eram realizadas numa das margens, e, o lado oposto, onde havia maior abundância de pastagem, era usado para a incipiente pecuária. Conforme estudos de Lunckes, atividades agrícolas, como a plantação da mandioca e da cana-de-açúcar, estavam diretamente 
relacionadas ao trânsito das tropas que usavam a zona litorânea como corredor de passagem. Duplamente importantes, a farinha de mandioca e a aguardente garantiam a subsistência dos agricultores e alimentavam os soldados. Ao chegar ao rio Tramandaí, o cientista ocupou-se em descrever o aspecto desértico da região, as choupanas construídas às margens do rio e a importância da pesca para a população pobre.

De acordo com a descrição de Saint-Hilaire, melhores acomodações só foram encontradas nas localidades de Pitangueiras e Boa Vista. A partir daí, o cientista hospedou-se em casas de melhor qualidade, tanto na construção, quanto no mobiliário. Em Boa Vista, pernoitou na fazenda homônima, onde estava sendo construído um curtume. Além desse empreendimento, seis mil vacuns e quinhentos cavalos pastavam em seus campos; já o trabalho era executado por 80 escravos. Saint-Hilaire impressionou-se com a fazenda e pôde dialogar com o Sr. Gavet, curtidor francês que ali se empregou. Antes de chegar a Porto Alegre, conheceu a Vila de Viamão, em 20 de junho, onde fez sua última parada. Aí, impressionou-se com a igreja e com as lides do campo, o que registrou como "fazer o rodeio".

Do diário de Saint-Hilaire, verifica-se que agiu como cientista, uma vez que registrou e coletou inúmeras plantas; de igual modo, preocupouse em descrever a fisionomia das pessoas, seu vestuário e acomodações, a economia local - agricultura, pecuária, pesca, curtume - e a natureza, com destaque para as torres e as lagoas. Quando descreveu o tipo físico dos litorâneos, comparou-os com modelos que estavam formatados em sua mente e cultura. Isso pode ser facilmente percebido quando falou dos indígenas, dos escravos e dos homens livres e pobres. A rudeza de suas aparências como que chocou o observador. No que tange à descrição das lagoas, ao que parece, Saint-Hilaire teve dificuldade em acompanhar o manancial de águas formado pelas diversas lagoas do LNRS. Iniciando sua trajetória em Torres, considerou a possibilidade de que todas as lagoas seguintes fariam parte desta primeira (lagoa da Itapeva). Foi somente na localidade de Pitangueiras que explicaram ao cientista que existiam outras lagoas, as quais se comunicavam por meio de canais.

Ainda, fazendo-se uma análise mais geral dos registros de SaintHilaire, pode-se dizer que os aspectos relacionados à geografia, à natureza, à economia e à composição social tiveram primazia sobre outros. Em relação ao espaço, o autor o considerou praticamente vazio, deixando de fazer menção à passagem das tropas pela região. É de se estranhar o silenciamento do autor, uma vez que o espaço compreendido 
entre Laguna e o extremo Sul (hoje, o Uruguai) havia se constituído em corredor de passagem, isto é, área de trânsito para tropas, missionários jesuítas, indígenas livres e em deslocamento forçado, aprisionadores de indígenas, comerciantes, aventureiros, desertores, comerciantes, criadores de gado, entre outros que, antes e depois do século XVI, trilhavam pela região. Como observador, Saint-Hilaire selecionou certas imagens para serem registradas, em detrimento de outras. Em decorrência disso, leu-se e estudou-se o diário de Saint-Hilaire como um recorte, como representação de uma certa realidade vivenciada pelo cientista.

O próximo viajante analisado neste texto foi o militar suíço Carl Seidler ${ }^{3}$, o qual passou pelo LNRS no ano de 1829. Portanto, nove anos depois de Saint-Hilaire. Seidler estava em Porto Alegre, onde requisitou o soldo devido pelo Estado há mais de dois anos. O motivo pelo qual regressou à província de Santa Catarina estava relacionado à "ordem imperial [que] manda que regressem aos seus batalhões ou regimentos todos os oficiais transferidos para outro corpo" (p. 224). A partir disso, conseguiu cavalos para empreender viagem de Porto Alegre até Laguna ou Desterro (Florianópolis). Neste texto, deixarse-á de lado a descrição da capital rio-grandense, para, imediatamente, se analisar a trajetória de Seidler a partir da "Freguesia de Viamão". Dessa localidade, destacou a igreja, "enriquecida de toda espécie de ornatos fabulosos" e a parca agricultura. O militar chegou a salientar que "não há nada plantado, absolutamente nada". Seguindo viagem, atravessou o rio Capivari, sob forte chuva, o que fez com que pernoitasse numa "miserável venda, inteiramente isolada". A próxima localidade alcançada foi a Freguesia de Conceição do Arroio, hoje Osório, de onde alcançaram o rio Tramandaí. O restante da viagem se deu mais próximo do mar, o que causou profunda nostalgia no viajante. Do seu relato, destaca-se:

Por fim, chegados à borda escarpada do mar, fiquei parado de braços cruzados, a olhar em silêncio, cheio de saudade, por sobre a intérmina superfície do oceano. Só quem algum dia, distante muitas centenas de léguas de seu torrão natal, depois de anos de luta,

“Além dos naturalistas, outros viajantes escreveram sobre o nosso país, deixando, por vezes, livros de valor para o conhecimento e os estudos da época, principalmente sobre o aspecto histórico e sociológico. Basta mencionar os alemães von Leithold, Rango, von Weech e os três mercenários Boesche, Schlichthorst e Seidler que, sem dúvida, em virtude do caráter mais popular de suas obras, contribuíram bastante para divulgar o conhecimento do Brasil nos países da Europa Central”. (Oberacker, 1997, p. 129). 
recorda com apaixonada afeição a pátria amada, pode realmente compreender as sensações inundantes que eu havia de experimentar naquele momento, quando deparei com a imensidade imperscrutável do oceano. (Seidler, 1980, p. 227).

Ao chegar a Torres, Seidler deparou-se com uma comemoração referente à vitória de um colono alemão para o cargo de juiz de paz. $\mathrm{O}$ viajante relatou que foram acolhidos pela comunidade local, de tal forma que participaram da festa, comeram, beberam e dialogaram com as autoridades ali presentes. Depois disso, Seidler aproveitou para visitar as comunidades do interior, onde presenciou a forma de viver dos colonos alemães católicos recém-instalados entre as lagoas do Morro do Forno e do Jacaré. A Colônia de São Pedro de Alcântara, onde estavam os colonos, distava "5 a 6 léguas" da vila torrense. A primeira observação de Seidler foi sobre a qualidade do solo: "em parte o terreno nesta região é muito fértil, mas também outra parte é tão pedregoso ou a tal ponto coberto da mais densa, impenetrável mata, que o agricultor estrangeiro tem de lutar..." (p. 230). O viajante responsabilizou o governo pela má distribuição das terras, inclusive, da divisão da Colônia em dois grupos: católicos, mais perto de Torres, os quais ganharam as melhores terras, e protestantes, mais distantes, no Vale do rio Três Forquilhas, onde estariam, segundo o autor, as terras de pior qualidade.

O segundo aspecto observado por Seidler em relação aos colonos é o conflito com os índios. De acordo com o autor, os colonos que estavam mais para dentro da mata ou mais distantes de seus vizinhos, viramse, muitas vezes, atacados por grupos de índios. A impossibilidade de plantar ou de colher teria levado muitas famílias a retornar a São Leopoldo, onde estariam mais seguras e distantes dos ataques. Da mesma forma, a quantidade de animais existentes na região era tamanha que, muitas vezes, destruíam parte das plantações. Seidler listou alguns deles, como a capivara, a "onça malhada", os papagaios e os macacos. Porém, as críticas do viajante são dirigidas, especialmente, às autoridades, as quais não pagavam, regularmente, o "auxílio pecuniário" prometido aos colonos. Por algumas páginas, o militar suíço que se desentendeu com as autoridades em Porto Alegre dirige severas críticas aos governos imperial e provincial no que diz respeito à imigração e aos cuidados que os colonos deveriam receber desde a sua chegada e instalação no Brasil.

Embora tenha uma linguagem mais rebuscada, muitas vezes quase poética, Seidler é bem mais crítico com o governo do que os outros dois viajantes ora analisados. Ao que parece, Saint-Hilaire e Roquette- 
Pinto agiram como cientistas, muito mais preocupados em descrever a paisagem do que analisar a situação dos moradores da região e criticar o governo por determinada conduta. Depois de Torres, Seidler adentrou a província catarinense em direção a Laguna.

Roquette-Pinto, o terceiro viajante analisado neste texto, ao intitular seu relatório, deu ênfase à "região das lagoas" do Rio Grande do Sul. Com uma pequena canoa, percorreu as águas de Tramandaí a Torres, descrevendo, em detalhes, a fauna e a flora local. Como cientista enviado pelo Museu Nacional, Roquette-Pinto investigou e coletou material de diversos sambaquis, cuja análise resultou no relatório ora estudado. No que se refere à excursão do cientista pelo LNRS, destacaram-se cinco temas para serem discutidos: as lagoas e os rios, as vilas, os sambaquis, a fauna e a flora, e a pesca (produção de bagre).

Sobre as lagoas e os rios do LNRS, Roquette-Pinto aproveitou a ligação que havia entre elas para percorrer a área compreendida entre Tramandaí e Torres. O tamanho das lagoas e o aspecto das águas, a correnteza, os canais de ligação, as chuvas e tempestades enfrentadas, enfim, as experiências vivenciadas a bordo da pequena canoa integraram os registros do autor. No que se refere às vilas que Roquette-Pinto encontrou, Cidreira e Tramandaí já são apontadas como praia de veraneio para a população de Porto Alegre 4 . O trajeto de Porto Alegre até Palmares era realizado num vapor (barco) e, daí para Cidreira, a cavalo, a qual contava, naquele momento, com 20 choupanas. Tramandaí, por sua vez, constituía-se num grande centro de pesca, com 100 casas de madeira, todas de propriedade dos pescadores, e 2 hotéis (todas as construções com características rudimentares: parede de madeira e telhado de palha, inclusive os hotéis). Sobre as vilas que estavam mais para o interior, junto à Serra Geral, a de São Pedro de Alcântara foi descrita como um lugarejo quase deserto. De acordo com o autor:

$\mathrm{O}$ aspecto das casas era decadente. Apesar do clima, ideal, da uberdade do solo, a colônia declinou porque foi estabelecida no meio da solidão, longe de qualquer centro consumidor ou exportador, sem poder transportar os produtos da terra. O arraial de São Pedro, perdido naquela serra, entre vales belíssimos, tinha o ar de uma vila abandonada (Roquette-Pinto, 1962, p. 31).

Já a vila de Maquiné e da Barra do Ouro, esta última colonizada por italianos [e também por poloneses], localizadas num vale estreito junto

4 Sobre a prática do veraneio no LNRS, ver o trabalho de Eloísa Ramos, no qual a autora discute a "invenção da praia” em Tramandaí e Torres (RAMOS, 2007, p. 297-303). 
à Serra Geral, foram descritas como lugarejos de maior prosperidade, onde o feijão, o milho, o arroz e o café eram plantados e colhidos com abundância. Apesar disso, Roquette-Pinto observou a dificuldade em se comercializar o que era produzido nas propriedades agrícolas, devido, principalmente, à distância de centros consumidores maiores.

Quando descreveu Tramandaí, Roquette-Pinto percebeu a importância da pesca do bagre para aquela localidade. Pesca, processamento e exportação movimentavam a modesta economia dos pescadores, os quais despachavam fardos de 75 quilos de bagre seco para Porto Alegre e, daí, para o Rio de Janeiro. Ao longo de duas páginas (22 e 23), o cientista detalhou o processo da pesca, da limpeza, da salgação, da secagem e do empacotamento dos fardos. Ao final, sentenciou: "As muitas lagoas que conheço no litoral do Rio Grande do Sul serão, talvez, mais tarde, tanques colossais onde a cultura do peixe se fará com imensa vantagem". (p. 23). Do ponto de vista econômico, nem a iniciativa privada, nem o poder público observaram as palavras de Roquette-Pinto quanto às possibilidades econômico-sociais decorrentes da exploração sustentável das lagoas do LNRS. Passado mais de um século desde a excursão do cientista pela região, nem mesmo o setor de turismo foi capaz de elaborar projetos que vislumbrassem as lagoas como elemento fundamental para o desenvolvimento do litoral.

Ao excursionar pelo LNRS, a fauna e a flora litorânea impressionaram o cientista. Vegetação diversificada, pássaros dos mais diversos tipos, jacarés, capivaras, entre outros animais, despertaram o interesse do jovem investigador. Segundo o autor: "paraíso de um caçador, ou melhor, regalo de um naturalista, chamemos, sem exagero, esta região lacustre do Rio Grande do Sul" (p. 28). O último aspecto do relatório de Roquette-Pinto a ser discutido diz respeito aos sambaquis, motivo maior da sua excursão. Foi para estudá-los que o cientista viajou do Rio de Janeiro até o LNRS. Ao se debruçar sobre os sambaquis de Arroio do Sal e Torres, Roquette-Pinto abordou a existência de grupos indígenas no litoral, tanto os que ficavam mais próximos do mar, quanto os que costumavam acampar junto às lagoas. Em termos de localização dos sambaquis, estes se encontravam numa vasta região entre Cidreira e Torres. Roquette-Pinto os visitou, investigou e coletou material. A análise foi realizada posteriormente, já no Rio de Janeiro, e deu origem ao presente relatório (a análise ocupou as páginas 36 a 46 do relatório elaborado pelo cientista).

Depois de sistematizar o que cada um dos viajantes escreveu sobre o LNRS, é possível realizar algumas comparações entre eles. 
Em termos de desenvolvimento urbano, o relatório de Roquette-Pinto não demonstra, com nitidez, se houve crescimento significativo ao longo de quase um século (1820/1829 - 1906). Ao que parece, as vilas mencionadas não se desenvolveram de forma acelerada desde que SaintHilaire e Seidler passaram pelo LNRS. No entanto, é possível perceber que a vila de pescadores de Tramandaí evoluiu graças à pesca do bagre. Quando da passagem de Saint-Hilaire, a região era composta de algumas choupanas; já quase um século depois, Roquette-Pinto observou que a vila era formada por 100 casas de pescadores e 2 hotéis que atendiam os veranistas da capital rio-grandense. Por outro lado, houve vilarejos que, segundo a descrição destes viajantes, no mínimo, não se desenvolveram como era esperado pelas autoridades da época. Seidler, ao mencionar a Colônia de São Pedro de Alcântara, registrou as dificuldades que os colonos estavam enfrentando, principalmente o ataque dos indígenas, a investida de alguns animais sobre suas plantações e o descaso das autoridades. Em 1906, quando Roquette-Pinto visitou a localidade, suas impressões foram de retrocesso, ou seja, a Colônia não só deixou de prosperar, como perdeu muitos de seus agricultores. Quanto à observação e registro do que foi visto, Roquette-Pinto e Saint-Hilaire se aproximam, pois atuaram, precisamente, como cientistas. Carl Seidler, por sua vez, foi um militar, cuja passagem pelo LNRS se deu em função de uma ordem imperial. Seidler estava preocupado com o seu pagamento, o qual estava em atraso há dois anos. Isso pode ter colaborado para que tivesse um posicionamento mais crítico em relação às autoridades.

Saint-Hilaire e Carl Seidler passaram pelo LNRS em 1820 e 1829, respectivamente. Entre a passagem de um e de outro, está a colonização alemã em Torres, efetuada a partir de 17 de novembro de 1826 . Aspectos da fala de Seidler não aparecem na fala de Saint-Hilaire pela ausência do fato histórico (leia-se, a instalação da Colônia alemã das Torres). Portanto, o espaço social descrito por Saint-Hilaire é outro se a colonização for tomada como parâmetro. Já o mundo experimentado por Seidler tem novos agentes históricos, novas relações sociais, novas tensões e conflitos sociais, novo desenvolvimento econômico, embora o cenário paisagístico guarde ingredientes quando da passagem de SaintHilaire pela região, como as próprias torres, o rio Mampituba, a lagoa da Itapeva, entre outros. A partir dos registros elaborados pelos viajantes, há a possibilidade de se construir "mapas mentais", isto é, descrever a região visitada através de mapas, desenhos ou croquis construídos a partir do que cada viajante relatou. Acidentes geográficos, resquícios de ocupação indígena, vilas, empreendimentos agrícolas, comerciais e/ou 
industriais, obras públicas, como pontes e postos de pedágio, entre outros marcos importantes, podem se constituir em elementos significativos para a criação de "mapas mentais" do LNRS. Dessa forma, os elementos presentes na geografia, na fauna e na flora são complementados por tudo aquilo que foi gerado através da interferência humana. A sobreposição de "mapas mentais" de diferentes épocas não só registrariam a paisagem de determinado momento, mas permitiriam observar como a região foi modificada pelos inúmeros agentes históricos que a percorreram em épocas distintas.

Ainda, não seria totalmente descabido salientar que Saint-Hilaire fez sua trajetória do sentido Norte para o Sul; portanto, seu campo de visão foi outro se comparado ao de Seidler e Roquette-Pinto, que excursionaram do Sul para o Norte, ou seja, de Tramandaí para Torres. $\mathrm{O}$ que cada um viu e registrou foi captado por ângulos de visão que diferem, sim, dependendo do sentido em que se está caminhando. As visões litorâneas de cada viajante - do mar à Serra Geral - foram transformadas em linguagem escrita, a qual nos permite outra viagem, isto é, tentar imaginar, desde o escrito, o que os olhos de cada um captaram.

\section{Referências}

CARDOSO, Sérgio. O olhar viajante (do etnólogo). In: NOVAES, Adauto (Org.). $O$ olhar. São Paulo: Companhia das Letras, 1988, p. 347-360.

CORBIN, Alain O território do vazio. A praia e o imaginário ocidental. São Paulo: Companhia das Letras, 1989.

ELY, Nilza Huyer (Org.). Torres tem história: Ruy Ruben Ruschel. Porto Alegre: EST, 2004.

FLECK, Eliane Cristina Deckmann. De terra de ninguém à terra de muitos: olhares viajantes e imagens fundadoras (do século XVII ao XIX). In: CAMARGO, Fernando, GUTFREIND, Ieda e REICHEL, Heloisa (Orgs.). Colônia. Passo Fundo: Méritos, 2006, p. 273-307. [Coleção História Geral do Rio Grande do Sul].

LEITE, Ilka Boaventura. Antropologia da viagem: escravos e libertos em Minas Gerais no século XIX. Belo Horizonte: UFMG, 1996.

LUNCKES, Mariseti Cristina Soares. Um velho projeto com novos rostos: uma colônia alemã para a Ponta das Torres. São Leopoldo, 1998. Dissertação [Mestrado]. História da América Latina. Programa de Pós-Graduação em História - UNISINOS, 1998.

MEYER, Maximiliano. A questão da recente vilegiatura marítima através da imigração alemã. In: DREHER, Martin N. et al (Orgs.). Saúde: corporeidade - educação. São Leopoldo: Oikos, 2009, p. 264-271. (CD-ROM).

MINDLIN, José E. Viajantes no Brasil: viagem em torno de meus livros. In: Estudos Históricos, Rio de Janeiro, Vol. 4, n. 7, 1991. 
MURARI, Luciana. Natureza e cultura no Brasil (1870-1922). São Paulo: Alameda, 2009.

NAXARA, Márcia Regina Capelari. Cientificismo \& sensibilidade romântica. Brasília: Editora UNB, 2004.

OBERACKER, Carlos. Viajantes, naturalistas e artistas estrangeiros. In: HOLLANDA, Sérgio Buarque de. História Geral da Civilização Brasileira. Rio de Janeiro: Bertrand Brasil, 1997. n. 3, tomo II, $1^{\text {o }}$ v., p. 119-131.

RAMOS, Eloísa Helena Capovilla da Luz. Dunas e vegetação arbustiva no Litoral Norte/RS cedem lugar a aprazível espaço de lazer ou a invenção da praia. In: ELY, Nilza Huyer (Org.). Arroio do Sal: marcas do tempo. Porto Alegre: EST, 2007. p. 297-303.

ROQUETTE-PINTO, E. Relatório da excursão ao litoral e à região das lagoas do Rio Grande do Sul. Porto Alegre: Gráfica da UFRGS, 1962.

SAINT-HILAIRE, Auguste de. Viagem ao Rio Grande do Sul. 4. ed. Porto Alegre: Martins Livreiro Editor, 2002.

SCHOSSLER, Joana Carolina. "Grüße vom Strand”: imagens da vilegiatura marítima no litoral gaúcho. In: DREHER, Martin N. et al. (Orgs.). Saúde: corporeidade - educação. São Leopoldo: Oikos, 2009. p. 226-234. (CD-ROM)

SEIDLER, Carl. Dez anos no Brasil. Belo Horizonte: Ed. Itatiaia; São Paulo: Editora da Universidade de São Paulo, 1980.

SILVA, Wilton Carlos Lima da. As terras inventadas. Discurso e natureza em Jean de Lèry, André João Antonil e Richard Francis Burton. São Paulo: UNESP, 2003.

SÜSSEKIND, Flora. O Brasil não é longe daqui: o narrador, a viagem. São Paulo: Companhia das Letras, 1990.

WITT, Marcos Antônio. Um juiz de paz alemão? Em Torres? Em 1829? Sim, conforme os relatos do viajante Seidler. In: ARENDT, Isabel Cristina; WITT, Marcos Antônio (Orgs.). História, cultura e memória: 180 anos de imigração alemã. São Leopoldo: Oikos, 2005. p. 224-228. 